tion may be either hot or cold when precipitated, but it should stand several hours before filtering, and should be cold when filtered. The residue is washed with 50 per cent. acetic acid and finally with water. Before using this method the bulk of the iron must be removed by some other method. Since the precipitate of iron with nitroso- $\beta$-naphthol is very bulky, 0.05 gram of iron is about the maximum quantity that can easily be handled on a $12 \mathrm{~cm}$. filter paper. The indium precipitated by electrolysis from a solution containing indium sulphate and quite large amounts of ferric sulphate and strongly acidulated with sulphuric acid, contains only small amounts of iron. This metal can then easily be freed from the iron that it still contains by precipitating the iron with nitroso- $\beta$-naphthol. Colorimetric analysis of the indium, after the precipitation of the iron by this method, showed that the content of iron was very low. This small amount of iron ${ }^{1}$ could easily have been introduced into the solution during evaporation by the dust from the air. Quantitative determinations of the iron remaining in the indium gave the following results:

\begin{tabular}{|c|c|c|}
\hline $\begin{array}{l}\text { Indium } \\
\text { oxide taken. } \\
\text { Gram. }\end{array}$ & $\begin{array}{l}\text { Perric } \\
\text { oxide added. } \\
\text { Gram. }\end{array}$ & $\begin{array}{c}\text { Nitroso- } \\
\text { naphthol used. } \\
\text { Gram. }\end{array}$ \\
\hline o. 3148 & 0.0328 & 5.0 \\
\hline o. 1738 & 0.0262 & 4.0 \\
\hline 0.2184 & 0.0197 & 3.0 \\
\hline $0.306 \mathrm{I}$ & 0.0262 & 2.5 \\
\hline 0.2142 & 0.0262 & 2.5 \\
\hline
\end{tabular}

Ferric oxide still
present in the indium oxide.
Gram.
Less than 0.00005
" " 0.00005
" 0.00005
" 0.0001
Very faint red

Some indium remains in the residue with the iron and a second precipitation will not remove all of it. The indium in these residues can easily be detected with the spectroscope. The total quantity of indium that is lost in these iron residues is, however, quite small, as is shown by the following data:

$\begin{array}{cccccc}\begin{array}{c}\text { Indium } \\ \text { oxide taken. } \\ \text { Gram. }\end{array} & \begin{array}{c}\text { Ferric } \\ \text { oxide added. } \\ \text { Gram. }\end{array} & \begin{array}{c}\text { Ferric oxide obtained from } \\ \text { First } \\ \text { precipitation. } \\ \text { Gram. }\end{array} & \begin{array}{c}\text { Indium oxide in ferric oxide in } \\ \text { precipitation. } \\ \text { Gram. }\end{array} & \begin{array}{c}\text { First } \\ \text { preciptation. } \\ \text { Gram. }\end{array} & \begin{array}{c}\text { precipitation. } \\ \text { Gram. }\end{array} \\ 0.3061 & 0.0262 & 0.0286 & 0.0273 & 0.0024 & 0.001 \text { I } \\ 0.1520 & 0.0262 & 0.0283 & 0.0273 & 0.0021 & 0.001 \mathrm{I} \\ 0.2142 & 0.0262 & 0.0281 & 0.0266 & 0.0019 & 0.0004\end{array}$

CORNELL UNIVERSITY,

December, 1907.

\title{
SOME NEW COMPOUNDS OF INDIUM.
}

By F. C. Mathers and C. G. Schluederberg.

Received December 16, 1907.

This paper describes the preparation and properties of four new compounds of indium: the perchlorate, the iodate, the selenate, and the caesium-selenium alum.

${ }^{1}$ Stokes and Cain, This Journal, 29, 409 (1907). 
Indium Perchlorate, $\operatorname{In}\left(\mathrm{ClO}_{4}\right)_{3} \cdot 8 \mathrm{H}_{2} \mathrm{O}$.- - Metallic indium was dissolved in dilute perchloric acid. This solution was evaporated upon a hot plate to a concentration such that when cooled in a mixture of ice and salt, small crystals were formed. The beaker was then placed in a vacuum desiccator containing concentrated sulphuric acid where the crystallization continued in a satisfactory manner. The crystals were rapidly rinsed with a small amount of water, dried on filter paper, and then placed in the vacuum desiccator for a short time.

The metallic indium that was used had been deposited electrolytically and then fused in a charcoal crucible in a current of hydrogen. This fusion was necessary to remove salts that were occluded from the electrolyte. The perchloric acid that was used was purchased from Schuckhardt. It contained a small quantity of sulphuric acid, which was removed by the addition of the proper allount of barium hydroxide.

Two different methods were used to determine the indium in the indium perchlorate. The shorter procedure consists in heating the sample to a temperature of about $200^{\circ}$, at which decomposition of the perchlorate takes place, then evaporating with nitric acid, and finally igniting the nitrate to the oxide. In the other method the indiun is precipitated as the hydroxide with ammonimm hydroxide and is weighed as the oxide. The second method is preferable, since it permits determinations of both the indium and the chlorine $\left(\mathrm{ClO}_{4}\right)$ in the same sample. To determine the chlorine, the filtrate from the indinm hydroxide was treated with an excess of sodium carbonate and a few drops of potassium permanganate. It was then evaporated to dryness on a water-bath and heated to near fusion, this treatment decomposing the perchlorate and vielding a chloride. The mass was dissolved in dilute nitric acid and the solution was freed from the insoluble manganese dioxide by filtration. The chlorine in the filtrate was precipitated and weighed as silver chloride.

\begin{tabular}{|c|c|c|c|c|c|}
\hline & $\begin{array}{c}\text { Theory for } \\
\text { In (ClO })_{3} .8 \mathrm{H}_{2} \mathrm{O} \\
\text { Percent. }\end{array}$ & & $\begin{array}{l}\text { Found. } \\
\text { Per cent }\end{array}$ & & \\
\hline$m$ & 24.92 & 24.82 & 24.73 & ; & $24.83^{3}$ \\
\hline Chlorine & 19.08 & $\$ 9.05$ & ; $\quad 18.67$ & ; & $\ldots$ \\
\hline
\end{tabular}

Attempts to make direct determinations of the water were unsuccessful on account of decomposition and the formation of a basic salt with a loss of chlorine. Samples of the crystals that had been dried for several hours in the vacuum desiccator gave higher values for the indium oxide, 25.4 and 25.7. These values agree with the theory for $\operatorname{In}\left(\mathrm{ClO}_{4}\right)_{3} \cdot 7 \mathrm{H}_{2} \mathrm{O}$. This is evidently due to the loss of water of crystallization, since several different samples that were dried for only a few minutes gave results that showed 8 molecules of water.

Indiun perchlorate is a colorless, crystalline, deliquescent compound

1 Determined by Method $\mathbf{r}$. 
that is soluble in water and in absolute alcohol, but much less soluble in ether. It easily forms saturated solutions in water. Basic salts are precipitated from a neutral water solution when the temperature is raised to $40^{\circ}$. When heated in the open air, the crystals fuse at about $80^{\circ}$, but do not form a clear liquid. When the heating is carried to a higher temperature, but not to a red heat, the substance decomposes with a liberation of chlorine. The residue is insoluble in water, but is easily soluble in dilute nitric acid, and this solution gives a strong test for chlorine.

Indium lodate, $\operatorname{In}\left(\mathrm{IO}_{3}\right)_{3}$. - Anhydrous indium trichloride was prepared and sealed off in a glass tube by a method previously described. ${ }^{1}$ Potassium iodate was recrystallized twice from water. This sample was analyzed by treating it with dilute sulphuric acid and potassium iodide and titrating the iodine that was liberated. Taken, $0.0750 \mathrm{~g} . \mathrm{KIO}_{3}$; found, $0.0749 \mathrm{~g}$.

Equivalent quantities of the indium trichloride and of potassium iodate were dissolved separately and then mixed. A precipitate formed immediately but it showed no crystalline structure when examined with a microscope. The entire solution was evaporated to dryness upon a water-bath and the residue was collected upon a Gooch crucible and was thoroughly washed with cold water. ${ }^{2}$ The crucible and contents were dried over sulphuric acid in a vacuum desiccator. Analyses of several samples prepared in this way did not give constant results. The substance was then dissolved in boiling nitric acid ( $\mathrm{x}$ : Io by volume). On evaporation of this solution, the indium iodate separated in imperfect, broken crystals whose crystal system could not be determined. These crystals were washed with water and dried in a vacuum desiccator. The results of the analyses were as follows:

\begin{tabular}{|c|c|c|c|}
\hline \multirow{2}{*}{$\begin{array}{l}\text { Theory for } \operatorname{In}\left(\mathrm{IO}_{3}\right)_{3} \\
\text { Per cent. } \\
\ldots \ldots 21.71\end{array}$} & \multicolumn{3}{|c|}{$\begin{array}{l}\text { Found. } \\
\text { Per cent. }\end{array}$} \\
\hline & $21 \cdot 76$ & and & 21.93 \\
\hline$\ldots \ldots 59.53$ & 59.19 & and & $59 \cdot 30$ \\
\hline $\begin{array}{l}\text { Water at } 125^{\circ} \ldots \ldots \ldots \ldots \ldots \ldots \text { (decomposition, brown color) } \\
\text { Loss at } 160^{\circ} \ldots .08\end{array}$ & (2) & & \\
\hline
\end{tabular}

The indium was precipitated as the hydroxide with ammonium hy. droxide and was weighed as the oxide. The iodine was calculated from the titration with sodium thiosulphate of the iodine that was liberated when a sample was treated with potassium iodide and dilute sulphuric acid.

Indium iodate is a white, crystalline, anhydrous compound. It is soluble in 1500 parts of water at $20^{\circ}$ and in 150 parts of $I: 5$ nitric acid

${ }^{1}$ Mathers, This Journal, 29, 485 (1907).

2 This is the method employed in his research upon iodates by A. Ditte, Ann. chim. phys. (6), 21, I45 (I890). 
at $80^{\circ}$. All attempts to grow large crystals from these solutions were unsuccessful. It is soluble in dilute sulphuric acid and in hydrochloric acid, but the latter causes a decomposition with the liberation of chlorine. The crystals decrepitate when heated with a free flame, become brown in color and give off iodine vapor. If touched with a red-hot wire they explode and form a cloud of iodine vapor.

Indium Selenaie, $\mathrm{In}_{2}\left(\mathrm{SeO}_{4}\right)_{3} \cdot \mathrm{IOH}_{2} \mathrm{O}$.--Indium selenate was prepared by dissolving indium hydroxide in selenic acid, which had been made according to the following method:

Flue dust known to be rich in selenium was heated in a porcelain dish with a strong solution of potassium cyanide for several hours. On filtering, a clear, amber-colored solution of potassium selenocyanate, (KCNSe), was obtained. A current of filtered air was passed through this solution for several hours in order to separate any tellurium that might have been dissolved with the selenium. A small quantity of a dark colored precipitate that separated was filtered off. The filtrate was cooled to about zero degrees and cold, 50 per cent. hydrochloric acid, sufficient to entirely precipitate the selenium, was added, care being taken to add the hydrochloric acid slowly to avoid an appreciable rise of temperature. The selenium is thrown down as a bright red, amorphous precipitate, which was filtered off and thoroughly washed. This was redissolved in a ten per cent. solution of potassium cyanide, treated with air, precipitated in the cold as before, filtered off, washed very thoroughly and dried.

The selenium was then dissolved in concentrated nitric acid and the solution evaporated to dryness on the water-bath, redissolved in very dilute hydrochloric acid and again evaporated to dryness. The selenium dioxide thus obtained was dissolved in a little water and added to chlorine water, through which a stream of chlorine was allowed to bubble, thus oxidizing the selenium dioxide to selenic acid. After being thus treated for several hours with chlorine the liquid was freed as far as possible from cxeess of that gas by passing through it a current of air.

The solution of selenic acid was neutralized with copper carbonate and freshly precipitated copper hydroxide. The blue solution of copper selenate thus obtained was filtered, concentrated on the water-bath and set aside to crystallize. Blue triclinic crystals of copper selenate separated. These were recrystallized from water solution and again dissolved in water and the solution freed from copper by electrolyzing in a platinum dish at low current density. ${ }^{1}$ Electrolysis was continued until no test for copper could be obtained with either ammonium hydroxide, potassium sulphocyanate or potassium ferrocyanide in small

'R. Metzner, Compt. rend., I27, 54 (1898). 
portions of the solution. The solution of pure selenic acid thus obtained was treated with indium hydroxide. Indium selenate crystallized out in white, easily soluble, hygroscopic crystals. Analysis gave the following results:

$$
\begin{aligned}
& \text { Theory for } \mathrm{In}_{2}\left(\mathrm{SeO}_{4}\right)_{3} \cdot \mathrm{IOH}_{2} \mathrm{O} \text {. Found. } \\
& \text { Indium oxide. . . . . . . . . } 33.08 \\
& 32.9-33.0 \\
& \text { Selenium.................. } 28.30 \\
& 28.3-28.2
\end{aligned}
$$

Indium Caesium Selenate, $\mathrm{CsIn}\left(\mathrm{SeO}_{4}\right)_{2} \cdot \mathrm{I}_{2} \mathrm{H}_{2} \mathrm{O}$.-Caesium-indium-selenate, the alum, was made by crystallizing a solution of caesium selenate

\begin{tabular}{|c|c|c|}
\hline & $\begin{array}{l}\text { Theory for } \mathrm{CsIn}\left(\mathrm{SeO}_{4}\right)_{2} \mathrm{I}_{2} \mathrm{H}_{2} \mathrm{O} \text {. } \\
\text { Pet cent. }\end{array}$ & $\begin{array}{l}\text { Found. } \\
\text { Per cent. }\end{array}$ \\
\hline Selenium & $\ldots 21.18$ & 21.04 \\
\hline Indium, . & .. I 5.3 & $15 \cdot 5$ \\
\hline Caesium. & $\ldots \ldots \ldots 17.7$ & 17.8 \\
\hline
\end{tabular}
(prepared from caesium hydroxide and selenic acid) and indium selenate.

The alum crystallizes in beautiful colorless octahedra, belonging to the tetragonal system, which are soluble in water, efflorescent in the air and are of the following composition:

In the above analyses the selenium was determined by repeated precipitation with sulphur dioxide gas from a hot dilute solution of the salt. The precipitate was collected on a Gooch filter, and the filtrate was boiled down and again treated with sulphur dioxide. It was found necessary to repeat this operation several times in order to remove all of the selenium from the solution. The Gooch filter was dried at 102-5 and the selenium was weighed.

The indium was precipitated by ammonium hydroxide as the hydroxide from the hydrochloric acid solution of the salt, collected on an ashless filter, heated in a porcelain crucible and weighed as $\operatorname{In}_{2} \mathrm{O}_{3}$.

For the determination of the caesium, the selenium was first removed and the caesium was then precipitated from the chloride solution by chlorplatinic acid and weighed as caesium chlorplatinate.

CORNell University,

December, 1907.

\section{A NEW FORM OF COLORIMETER.}

BY GeORGE STEIGER.

Received November 6, 1907.

The many uses to which colorimeters can be put are too well known to need mention here.

Instruments using the principle upon which this one is based-the ratio of the thickness of the liquid through, and not the actual dilution to equal concentrations-are not applicable to all colorimetric determinations. It will be found, in comparing such a solution as is used in the colorimetric determination of manganese and some other substances, 